\title{
Cartografia do Ensino de Artes no Brasil: das Belas Artes a BNCC $^{1}$
}

\author{
Cartografía de la Enseñanza de Artes en Brasil: de las Bellas Artes a \\ $B N C C$
}

Cartography of the Teaching of Arts in Brazil: from the Fine Arts to BNCC

\begin{abstract}
Jésica Hencke ${ }^{2}$
João Alberto da Silva ${ }^{3}$

Resumo

O ensino de arte na Educação Básica brasileira configura-se por um sistema de avanços e retrocessos presenciados nos currículos escolares e nas leis que tangenciam ao ensino. Há poucas décadas obteve abertura para suas múltiplas formas de expressão: artes visuais, dança, teatro, música; na atualidade o que está em voga é a discussão da ambígua e reducionista BNCC - Base Nacional Comum Curricular - que apresenta o cinema, a performance e a literatura, como meios artísticos. Investiga-se de forma sumária e inicial quais os entraves, dilemas, possibilidades e perdas curriculares do ensino de artes visuais no Brasil, entre a faculdade de Belas Artes e a proposição da BNCC, de forma a gerir uma escrita genealógica das transformações curriculares até investigar os primeiros respingos e transformações educacionais provenientes da BNCC e seu viés científicotécnico-matemático. Neste sentido, no movimento de escrita se apresentou um panorama geral das transformações curriculares no Brasil, de forma a caminhar a um processo de proposição e pensamento da BNCC e o quanto está lei pode minorar o papel social conquistado pela arte. Pode-se destacar que a arte age na formação cidadã, no aprimoramento estético-cultural, investindo no saber sensível, ético e social do humano.
\end{abstract}

Palavras chave: Currículo; Educação; BNCC; Ensino de Arte; Educação Básica.

\section{Resumen}

La enseñanza de arte en la Educación Básica brasileña se configura por un sistema de avances y retrocesos presenciados en los currículos escolares y en las leyes que tienden a la enseñanza. Hace pocas décadas obtuvo apertura para sus múltiples formas de expresión: artes visuales, danza, teatro, música; en la actualidad lo que está en boga es la discusión de la ambigua y reduccionista BNCC - Base Nacional Común Curricular - que presenta el cine, la performance y la literatura, como medios artísticos. Se investiga de forma sumaria e inicial cuáles son los obstáculos, dilemas, posibilidades y pérdidas curriculares de la enseñanza de artes visuales en Brasil, entre la facultad de Bellas Artes y la proposición de la BNCC, para gestionar una escritura genealógica de las transformaciones curriculares hasta investigar las primeras salpicaduras y transformaciones educativas provenientes de la BNCC y su sesgo científico-técnico-matemático. En este sentido, en el movimiento de escritura se presentó un panorama general de las transformaciones curriculares en Brasil, de forma a caminar a un proceso de proposición y pensamiento de la BNCC y cuánto está ley puede mitigar el papel social conquistado por el arte. Se puede destacar que el arte actúa en la formación ciudadana, en el perfeccionamiento estético-cultural, invirtiendo en el saber sensible, ético y social de lo humano.

Palabras clave: Currículo; la educación; BNCC; Enseñanza de Arte; Educación básica.

\footnotetext{
${ }^{1}$ BNCC - Base Nacional Comum Curricular.

${ }^{2}$ Mestre em Artes Visuais pela UFPEL - Universidade Federal de Pelotas; Pelotas; RS; Brasil; jesicahencke@gmail.com

${ }^{3}$ Doutor em Educação pela Universidade Federal do Rio Grande do Sul-UFRGS; Porto Alegre; RS; Brasil; joaopiaget@gmail.com
} 


\begin{abstract}
The teaching of art in the Brazilian Basic Education is configured by a system of advances and setbacks witnessed in the school curricula and laws that relate to teaching. A few decades ago he was open to his multiple forms of expression: visual arts, dance, theater, music; at present, what is in vogue is the discussion of the ambiguous and reductionist BNCC - National Curricular Common Base - that presents cinema, performance and literature, as artistic means. The obstacles, dilemmas, possibilities and curricular losses of the teaching of visual arts in Brazil, between the Faculty of Fine Arts and the proposal of the BNCC, are investigated in a summary and initial way in order to manage a genealogical writing of the curricular transformations until investigating the first spills and educational transformations coming from the BNCC and its scientific-technical-mathematical bias. In this sense, the writing movement presented an overview of the curricular transformations in Brazil, in order to move to a process of proposition and thought of the BNCC and how much this law can reduce the social role conquered by art. It is possible to emphasize that art acts in the citizen formation, in the aesthetic-cultural improvement, investing in the sensitive, ethical and social knowledge of the human.
\end{abstract}

Keywords: Curriculum; The education; BNCC; Art Teaching; Basic education.

\title{
1. Introdução
}

Escrever é envolver-se, doar-se através de palavras, dar forma ao pensamento e questionar dilemas educacionais. Com a pretensão de produzir uma investigação que possibilite ver a arte visual ou as artes, enquanto substrato formativo alicerçado em dilemas, questionamentos e investigações curriculares desdobra-se o presente texto.

As linhas traçadas que compõem esta escrita são momentos de desaceleração e aceleração num percurso, acerca de um questionamento: Quais os entraves, dilemas, possibilidades e perdas curriculares do ensino de artes visuais no Brasil, num percurso genealógico entre a faculdade de Belas Artes e a proposição da BNCC?

Nesta escrita o objetivo é investigar o processo de transformações históricocurriculares sofridos pelas escolas da rede pública, percorrendo as múltiplas leis e adequações que o ensino de artes visuais vivenciou desembocando na atual BNCC e seu viés científicotécnico-matemático.

Diante de uma perspectiva de investigação cartográfica a intenção do processo de revisão teórico-bibliográfica-propositiva tem como desafio pensar o currículo escolar à luz dos conceitos de sensação, arte como produção de pensamento e experiência, tendo como pano de fundo um estudo genealógico, ao investigar o cerne de cada mudança curricular.

Destaca-se que a perda da arte como processo de criação que envolve o corpo, a imagem, a produção pictórica, fotográfica, performática e intervenção coletiva, que num fluxo curricular esteve presente e ausente no verbo da lei, passa, na atualidade, a ser inexistente, há um currículo "assentado" que trabalha arte como linguagem e comunicação, valorando os processos de interpretação e análise. 
Etimologicamente o termo currículo provém do verbo latino currere que significa correr, ultrapassar obstáculos para chegar a um resultado final padronizado, a construção de uma carreira (SACRISTÁN, 2000). Pode ser compreendido como um modo de organizar uma série de práticas educativas que viabilizam a formação de um modelo de cidadão socialmente ativo.

Parte-se da compreensão de que a legislação educacional e sua estrutura legalizada mantêm uma estratégia positivista e tecnicista que valoriza a área das Ciências Exatas, contribuindo a um processo formativo naturalizado e constituído por um ideal objetivo, sistemático e cartesiano de educação, sufocando de forma hábil a composição de uma episteme artesanal e subjetiva das ciências humanas, na qual o próprio sujeito se torna o objeto do conhecimento. Para Foucault (2007) a ciência é contingente, um espaço de liberdade que possibilita uma vida singular, não está determinado, pode ou não acontecer, envolve-se com subjetividades.

De maneira geral, o currículo, apresenta-se como um mecanismo para demarcar os territórios de aprendizagem que podem ser percorridos em determinado espaço-tempo escolar e visa, sumariamente, apropriar-se da cultura cotidiana, dos valores sociais das classes consideradas dominantes e da distribuição social do conhecimento. Assim colocado, este sistema de estruturação curricular delimita o que é válido a ser transmitido e como se dará o processo avaliativo destes saberes. Ao descrever o que é válido a BNCC determina os conceitos que devem ser desenvolvidos em todo o Brasil, sem preocupar-se com as peculiaridades de cada região.

A BNCC prevê o desenvolvimento de seis dimensões que valorizam o processo estético para a apreensão de cada objetivo a ser desenvolvido, visto que não existe a demarcação de conteúdos. Dentre as dimensões propõe: criação, crítica, estesia, expressão, fruição e reflexão, que perdem sua potência quando as grandes áreas do saber se reduzem ao desenvolvimento de habilidades cognitivas. Outro dilema a ser evidenciado é a falta da sugestão de conteúdos, provocando um possível dês-comprometimento docente.

Dentro da estrutura curricular brasileira (escolarizada) disseminada nos séculos XIX e XX, a ênfase recai sobre o processo de planejamento que envolve: os objetivos, os conteúdos, as estratégias e a avaliação da aprendizagem, pois, o elemento principal é a organização técnico-burocrática das aulas. Sacristán (2000) em suas pesquisas a partir da teoria de Johnson (1967) pode evidenciar que o currículo apresenta-se como um conjunto de objetivos estruturados que se quer alcançar, desta maneira, existe uma dinâmica de meios-fins como um esquema racionalizador da prática pedagógica. 
Imerso nesta ação racionalizada de aprendizagem, o ensino de Artes Visuais transformou-se num processo de compreensão e exploração da linguagem artística, usurpando o processo de invenção, criação e produção de pensamentos. Desta forma retira-se do ensino a possibilidade de viver experiências, visto que sempre há um modelo a ser reproduzido.

Imerso neste processo de contradições a pesquisa em educação com ênfase nos caminhos curriculares associa-se a um método de investigação que provoca rupturas com a rigidez, a certeza e o modelo único, proporcionando uma ação cartográfica. $O$ ato de cartografar, configura-se pelo acompanhamento de percursos históricos e registros teóricos acerca do ensino de artes visuais no Brasil, propôs-se uma composição de processos, conexão ou criação de redes ou rizomas (PASSOS, KASTRUP, ESCÓSSIA, 2009), um dos objetivos é promover uma compreensão acerca do currículo como instrumento balizador das práticas educacionais, demarcador de objetivos dentro de uma genealogia que configura a essência do fazer educacional em artes visuais.

Construir um processo cartográfico rompe com o conhecimento dualista que separa natureza e cultura, objetivo e subjetivo, quantitativo e qualitativo. Constrói um conhecimento geograficamente localizado, transitório, reconhece a necessidade de formas plurais e múltiplas de registro, permite abarcar a complexidade, ao focar-se no problema de investigação. O olhar que tangencia a escrita limita-se pelas escolhas bibliográficas e a constituição do problema investigado, compõe um saber que emerge do fazer/investigar.

Pesquisar é ocupar um território, é circunscrever um espaço, é criar uma linha imaginária composta por multiplicidades de encontros, feita por segmentos e aberturas, disposta a romper-se e formar outras linhas, viver experiências, contagiar-se, abrir-se as porosidades e multiplicidades do plano educacional.

\section{Currículo: aproximações e mapeamentos}

[...] Currículo é lugar de representação simbólica, transgressão, jogo de poder multicultural, lugar de escolhas, inclusões e exclusões, produto de uma lógica explícita muitas vezes e, outras, resultado de uma "lógica clandestina", que nem sempre é a expressão da vontade de um sujeito, mas imposição do próprio ato discursivo. (BERTICELLI, 1998, p. 160).

Neste trecho de Berticelli (1998) há uma ponderação interessante ao falar de uma "lógica clandestina" que, passa a desarticular o projeto moderno e prevê a construção de um sujeito social individual imerso numa sociedade industrial. A este sujeito cabe desenvolver um conhecimento formativo em determinada área, exercer com habilidade sua profissão e possuir uma carreira, ou seja, construir seu currículo, prescrever a própria vida. 
A prescritividade demarca a origem do currículo como um documento universal e balizador das ações docentes, de forma a garantir uma aprendizagem igualitária a todos os estudantes/aprendizes; resume-se a um programa de estudos e/ou de formação.

"O currículo é sempre currículo para alguém, construído a partir de alguém” (BERTICELLI, 1998, p. 166), urge uma convencionalidade entre o que de fato é importante ensinar e o que não precisa ser aprendido pela massa social, por assim dizer. Conceber um currículo demanda vivência, experiência, intencionalidade, reflexão e embasamento teórico. Entre a concepção curricular e sua escrita há perdas e rupturas possibilitando a "lógica clandestina do compreender, do pensar e do escrever" (BERTICELLI, 1998, p. 167).

Silva (2010), por sua vez, realiza um convite à análise, compreensão e reflexão que traduz nossa forma de ver e perceber o currículo como potência para a construção das ações aprendentes, destaca a instabilidade das relações na contemporaneidade e os resquícios de nossas atitudes amparadas num ideal moderno. Em suas palavras:

\begin{abstract}
Vivemos num mundo social onde novas identidades culturais e sociais emergem, se afirmam, apagando fronteiras, transgredindo proibições e tabus identitários, num tempo de deliciosos cruzamentos de fronteiras, de um fascinante processo de hibridização de identidades (...). Paradoxalmente, vivemos, entretanto, também num tempo de desespero e dor, de sofrimento e miséria, de tragédia e violência, de anulação e negação das capacidades humanas (...). Vivemos num tempo de afirmação da identidade hegemônica do sujeito otimizador do mercado, num mundo onde zelosos guarda-fronteiras tentam conter a emergência de novas e de renovadas identidades e coibir a livre circulação entre territórios - os geográficos e os simbólicos. É uma desgraça, é uma danação, é uma tristeza, viver num tempo como esse, num tempo assim... (SILVA, 2010, p. 7-8).
\end{abstract}

Um tempo de tristezas e danações que se articula com a possibilidade de transformações curriculares, inebriado em relações de saber, poder e identidade. As políticas curriculares interpelam papéis, determinam individuações, incluem certos saberes individualizados, e excluem outros (SILVA, 2010). Neste processo de inclusão e exclusão de saberes estrutura-se o processo de ensino em Artes Visuais, o currículo apresenta-se como uma relação social orgânica e revela marcas das transformações sociais em sua produção.

$\mathrm{Na}$ abordagem de Berticelli (1998) o currículo exprime elementos da memória coletiva, expressa ideologias, conflitos simbólicos, de descobrimento e ocultamento, segundo os interesses sociais em jogo. “O currículo é um dos 'lugares' em que 'concede a palavra' ou 'se toma a palavra', no jogo das forças políticas, sociais e econômicas" (BERTICELLI, 1998, p. 168).

Sacristán (1999) destaca que "a educação tem funções a cumprir, só que estas ficaram desestabilizadas por mudanças políticas, sociais, culturais que estão acontecendo" 
(SACRISTÁN, 1999, p. 12). Acontecer, segundo o autor, significa o momento atual em que vivemos e as transformações que ocorrem neste plano geográfico, social e cultural no qual se está imerso.

As presentes mudanças produzem "ruídos" (SACRISTÁN, 1999), formando fissuras no ideal moderno das certezas, realidade, ordem, progresso, saberes universais e inquestionáveis, respingando na elaboração do currículo escolar e abalando a estática (o não movimento, a fixidez e a rigidez conceitual), na qual a "grade" curricular encontra-se alicerçada.

O que move a educação? A reprodução?! A imposição governamental?! As "grades" curriculares?! Sim, mas, não somente. Existe uma infinidade de possibilidades quando se pensa em processos e não em produtos. Enquanto processo analisa-se tempos e espaços percorridos, caminhos marcados por incertezas, entusiasmos, erros, quedas, conquistas, infelicidades, alegrias, movimentos e trajetórias que são suspensas e que dão espaço à existência de outros encontros, outras possibilidades, novas aprendizagens.

O currículo, embebido no modelo, na regra, no padrão, é "dogmático", "assentado" (CORAZZA, SILVA, 2003) construído de forma a gerir e organizar o processo metodológico de ensino e impossibilita perceber o aprender que existe no entre, no instável, no inusitado e na relação. Embasa-se em conteúdos e disciplinas escolares pensadas de forma fragmentada, hierárquica, correspondendo a um determinado modelo de sociedade.

O currículo dogmático demarca modos de aprender e de ensinar, ampara-se na representação do saber, na recognição dos conceitos e na recuperação das informações transmitidas pelos professores. O espaço educacional não é inerte, nem neutro, ele é disjuntivo, descontínuo, formado por rupturas, alterações e sensações, que abalam a estrutura curricular.

As práticas curriculares convencionais, presas como estão em paisagens extremamente tecnicistas e estéreis, raramente permitem que sejam feitas questões além daquelas relacionadas com utilidade, competência e medição [...]. Elas geram um espaço pré-fabricado que tende a ser estéril, uma vez que a percepção, no seu interior, continua sob o domínio da profunda superstição platônica da mente concebida como um espelho que reflete a realidade [...]. Como resultado, sobre uma tal superfície, a aprendizagem é vista como recuperação de um mundo que existe lá fora. (ROY, 2002, p.93, grifos do autor).

Roy (2002) apresenta o olhar assumido por muitas escolas na atualidade: rejeitar o novo, o diferente, recusar-se a assumir a heterogeneidade, a pensar a educação como um plano potencial de inovações, de criações e desafios, ao restringir-se à repetição e reprodução ininterrupta do mesmo, o igual, o conhecido e aceito como verdade consolidado por uma vertente educacional estruturalista, amparado em metanarrativas. O currículo outorgado e 
legitimado nas escolas trabalha com a universalização, padronização, cópia e reprodução de saber-conceitos.

É importante lembrar que o dogma curricular articula com verdades, determina um modelo único de saber-aprender-reproduzir, dialoga com o corpo máquina cartesiano que está a serviço de um ideal, visto que estrutura-se na matéria-forma, modelo legal (respaldado por leis), monocultural (enfatiza apenas uma cultura), promove a formação de bons cidadãos, bons saberes, bons valores, cujo ensino é firme, sólido, estável e estático. A missão deste currículo é monopolizar o saber, impedir que haja contaminação de saberes diversos, formas de aprender múltiplas, não fixas, não padronizadas, ultrapassando e desmistificando o pensamento e saber ajuizado, calmante, conformista, confortante, organizado (CORAZZA, SILVA, 2003).

E a escola, arcaica ao contemporâneo, alicerçada na ordem, no modelo, repleta de salas de aula retangulares, com lâmpadas fluorescentes, janelas gradeadas, classes enfileiras e quadros brancos ou de giz, reforça as normas ao introduzir outros corpos triviais nesta ordem prévia, para tentar "domesticá-los".

Iavelberg (2003) destaca que a partir da década de 90 (noventa) cada escola passa a ser responsável pela construção do currículo, não havendo definição de conteúdos mínimos para o país, mas sim, a existência dos Parâmetros Curriculares que pode ser compreendido entre uma norma a ser estabelecida, bem como, a possibilidade de variabilidade e alternância de conteúdos, objetivos, procedimentos avaliativos e métodos de ensino adaptados a cada realidade sociocultural e educacional. "O currículo precisa ser concebido como um projeto em permanente transformação, no qual a visão de educação e o papel da escola são constantemente reorientados, segundo os avanços teóricos e práticos dos temas e das questões a ele conectados" (IAVELBERG, 2003, p. 25).

Educar é possibilitar a criação. Criar pode ser um ato sofrível, que requer envolvimento, pensamento e persistência; ações que extrapolam o currículo "assentando", este documento (quase personificado) alicerçado numa sanção universal massificadora, estruturada no processo de matéria-forma, em que constrói sujeitos submissos a um sistema e perpetua um modelo, torna os fluxos do aprender estanques.

"O currículo é o lugar dos eventos micro e macro, dos sistemas educacionais, das instituições, há um tempo, e o lugar, também, dos desejos mínimos, por outro" (BERTICELLI, 1998, p. 175). Ao reconhecer o currículo como lugar de desejos e transformações vivencia-se uma metamorfose. 
Com base no exposto, passa-se a descrever o processo de escolarização brasileira no que tange ao ensino de Artes Visuais, numa tentativa de tornar visíveis os microeventos curriculares.

\subsection{O ensino de Artes Visuais no Brasil: amarras e fissuras curriculares}

Nesta teia de sentidos, que vai formando tessituras do saber, se mostra necessário perguntar: o que a escola e seu currículo ensinam em artes visuais? É possível ensinar? Enlameado pela técnica aborda-se a linguagem visual, materiais, formas, movimentos artísticos, desdobramentos entre luz e sombra, tonalidades, cor, desenho geométrico, perspectiva, figura-fundo, história da arte, leitura e releitura de imagens.

A arte-educação contemporânea, não precisa ser eterna, permanente, imutável, pode ser constituída pela miscigenação de materiais, tornando-se permeável, porosa, efêmera, penetrável, angustiante, questionadora, desestabilizadora. Dentro do contexto educacional o efêmero pode ser experimentado através de performances, instalações, inquietações, questionamentos que modificam as percepções.

Viver a arte, enquanto vida e obra não é apenas contemplar, observar e apreciar pinturas, esculturas, alto e baixo relevo, por exemplo, ações respeitadas e valorizadas na Idade Média. Na Idade Moderna entra em cena o espectador, de forma tímida e sutil ao desenvolver suas faculdades mentais e apreciar o belo e o sublime. Na arte contemporânea a ação critica flui, necessita-se sentir o ato de criar, permitir que a obra infiltre-se no imaginário do espectador-ator-participante levando-o ao questionamento, a dúvida, a um diálogo permanente entre o saber, quase saber, tentar saber, não-saber, o sentir, quase sentir, tentar sentir, nãosentir, o ver, quase ver, tentar ver, o não-ver tudo ao mesmo tempo, sem hierarquias. A arte apresenta-se num fluxo vital, o inesperado, torna-se vida, arte, ação, criação e pensamento.

Ferraz e Fusari destacam que as práticas educativas "surgem de mobilizações políticas, sociais, pedagógicas, filosóficas, e, no caso da arte, também de teorias e proposições artísticas e estéticas" (FERRAZ e FUSARI, 2009, p. 37). Inebriado por esta gama de variantes, o âmbito escolar torna-se prenhe de potencialidades para a criação, que, deveras, é acachapada sob a égide da "grade curricular", das disciplinas prático-científicas, da necessidade de produzir informações e viver experimentos, não experiências.

O currículo de Artes Visuais se apresenta como um patchwork de teorias inacabadas e sobrepostas, modelos provenientes de Portugal, França, Inglaterra, Espanha, Alemanha, Suíça e Estados Unidos. Séculos que se confundem, imposições que desrespeitam as construções 
nacionais e rompem com um modelo de ensino jesuítico alicerçado na gramática, retórica e humanidades.

As primeiras incursões artísticas no Brasil, após a expulsão dos jesuítas pelos portugueses, refere-se à tradição erudita barroco-rococó (que foi desenvolvida no Brasil em seus primórdios, pelos padres jesuítas e substituída pelo Maneirismo), sendo esta a construção de uma arte como produto cultural brasileiro, possuindo violento calor e emoção. Com a chegada da Missão Francesa houve a institucionalização do ensino de arte estruturada no modelo neoclássico e seu intelectualismo frio, uma arte da burguesia a serviço dos ideais aristocráticos, não há respeito pela arte nacional e sim um sufocamento (BARBOSA, 2009).

A Escola de Ciências Artes e Ofícios (1816) apresenta um currículo alicerçado na repetição dos modelos de ensino de atividades artísticas ligadas a ocupações mecânicas, propõe a introdução do desenho criativo para trabalhadores manuais e a inserção do desenho geométrico, num casamento entre belas artes e artes industriais. A Escola Imperial de Belas Artes (1826) dá abertura para a distinção entre educação de elite e educação popular, propondo uma dicotomia entre arte como criação e arte como técnica (BARBOSA, 2009).

Em 1855 Manuel José de Araújo Porto Alegre, procurou estabelecer uma cultura de elite e uma cultura de massa, entretanto "a permanência dos velhos métodos e de uma linguagem sofisticada continuou mantendo o povo afastado" (BARBOSA, 2009, p. 29) da compreensão artística, considerando-a supérflua, estabelecendo duas classes de alunos, os artistas e os artesãos. Em sua proposta de intervenção e transformação curricular não houve modificações quanto à metodologia, o desenho figurado continuou a ser cópia de estampas e modelos presentes na pedagogia neoclássica e, a pintura por sua vez, "continuou debatendo-se dentro dos princípios neoclássicos, nos quais tinham sido instruídos pelos mestres franceses, conseguindo apenas um abrandamento da rigidez de tais princípios" (BARBOSA, 2009, p. 29).

A partir de 1870 e com maior ênfase após a Abolição da Escravatura em 1888 e a República em 1889, defende-se uma educação popular voltada ao desenho industrial obrigatório no ensino primário e secundário, cuja ênfase é ampliada nos primeiros anos do século $\mathrm{XX}$.

O desenho teve um lugar de grande destaque no currículo secundário e especialmente no currículo primário, cujos respingos encontramos ainda hoje em muitos programas curriculares. Rui Barbosa foi um dos educadores brasileiros que mais se deteve ao ensino do desenho e da Arte no Brasil, sua teoria política liberal acreditava que a educação técnica e artesanal do povo era condição básica para o desenvolvimento industrial (BARBOSA, 2009), 
tal postura estava alicerçada nos estudos de Smith "[...] o fim é aprender a ver, a descobrir, a conservar, e recordar, a reproduzir, a criar, em suma, ou, para dizer tudo numa só palavra, o fim é instruir, é educar" (BARBOSA, 2009, p. 50), formando mão de obra apta a impulsionar o desenvolvimento tecnológico-industrial do país.

O ensino do desenho popularizou-se por ser considerado subsídio preparatório para o design, a criação de peças industriais, o desenvolvimento financeiro e social do país, sendo mais fácil a um médico desenhar o instrumento que poderá auxiliar em sua prática cotidiana, ao invés de explicá-lo ao artesão que irá produzi-lo, por exemplo. As ideias de Walter Smith, através dos estudos e elaboração do parecer do ensino secundário por Rui Barbosa, ecoaram no ensino da Arte por quase três décadas e, antes mesmo da publicação do Parecer sobre o Ensino Primário redigido pelo mesmo autor com ideias mais amplas, originais e pessoais embasado numa filosofia da educação, Abílio César Pereira Borges publicou o primeiro manual de desenho geométrico intitulado "Geometria Popular", cujo livro teve reconhecido destaque e repercussão, chegando a 1959 sua 41ª edição (BARBOSA, 2009).

"O estudo era iniciado pelas linhas retas, vertical, horizontal, oblíquas, inclinadas, paralelas e, a seguir, vinham os ângulos, triângulos, retângulos, numa gradação conteudística" (BARBOSA, 2009, p. 56), modelo presente na abordagem tradicional de ensino, que trata das menores partículas a serem ensinadas e vai se tornando complexo à medida que o conceito é apreendido.

A influência do positivismo na república brasileira não passou despercebida pelos currículos escolares, o aperfeiçoamento intelectual era considerado condição basilar para o desenvolvimento político e social, e a arte vista como "um poderoso veículo para o desenvolvimento do raciocínio desde que, ensinada através do método positivo" (BARBOSA, 2009, p. 67), subordinava a imaginação às leis que regem as formas científicas.

Foi com Benjamim Constant, durante a Primeira República, que ocorreu a reforma positivista e influenciou a evolução do ensino secundário, o qual passou a ser centrado no ensino das ciências; o desenho aparecia no currículo apenas como auxiliar deste processo. Nesta proposta curricular os conteúdos de geometria eram extensos e seu estudo excessivo, sendo pré-requisito para ascender a cursos superiores em nível Jurídico e/ou de Médico Cirúrgico, por exemplo.

Com a morte de Benjamim Constant ocorreu inúmeras modificações em sua Reforma Educacional, surgindo assim o Código Fernando Lobo. "Segundo esta lei o currículo passou a se orientar em direção à preparação do aluno para a escola superior, limitando-se os objetivos formativos ao simples desenvolvimento do raciocínio" (BARBOSA, 2009, p. 74), talvez este 
processo tenha tornado submissa à arte como criação, visto que o único objetivo curricular era possibilitar a ascensão a cursos superiores. Imerso nesta concepção formativa os positivistas “imprimiram ao ensino da Arte um excessivo rigorismo, baseado na ideia do princípio de ordenação das formas e na ideia de que o individual, enquanto elemento de expressão e composição, passa a ser insignificante para o próprio indivíduo” (BARBOSA, 2009, p. 74).

O Código Fernando Lobo, foi substituído pelo Código Epitáfio Pessoa que, entre os anos de 1901 e 1910 deixou de forma descoberta o ensino primário e valorizou o secundário, acarretando ao país uma grande perda no que tange à aprendizagem básica. Neste código educacional há uma articulação entre o liberalismo e o positivismo. Segundo a lei, o ensino do desenho deverá ter por base a morfologia geométrica, valendo-se de modelos naturais ao invés da reprodução de cartões impressos. A ênfase mantinha-se na existência da geometria descritiva, cujo ensino estava defasado em função das reformas educacionais e a falta de professores capacitados para seu desenvolvimento, assim, de forma simplificada o estudo do desenho geométrico apresentou-se nos currículos de Artes (BARBOSA, 2009).

[...] o primeiro ano deveria compreender: desenho de mão livre com aplicação especial ao ornato geométrico plano; o segundo ano, estudo de sólidos geométricos acompanhados dos princípios práticos de execução das sombras e ornatos em relevo; no terceiro ano, desenho linear geométrico, elementos de perspectiva prática e vista; no quarto ano, elementos de desenho geometral ou da representação real dos corpos (BARBOSA, 2009, p. 80).

Foi a partir desta simplificação do currículo, alicerçado na geometria, que o desenho tornou-se uma linguagem que pode ser aprendida como o ato de ler e escrever. Para os positivistas era interpretado como uma linguagem científica e instrumento para a racionalização das emoções e, para os liberais, uma linguagem técnica como meio de libertar a inventividade dos entraves da ignorância normativa (BARBOSA, 2009).

Em 1911, outra Reforma Educacional passa a vigorar no país ampliando ainda mais o leque de desencontros e entraves no processo de escolarização que se mantém elitizado, designada como Lei Rivadávia Correa. A presente lei retira a obrigação do Estado no que tange à elaboração dos currículos escolares, eximindo a existência da uniformidade dos programas, mantendo apenas a obrigação legal (pública) de prover recursos financeiros. Delega um modelo de autonomia didática administrativa às instituições de ensino, que a partir desta década deveriam elaborar seus programas de estudo, descrever os objetivos, desenvolver métodos de trabalho, articular o processo avaliativo, respeitando apenas o título II letra j da lei que versa sobre a obrigatoriedade do desenho no primeiro ano: "o Desenho na primeira série compreenderá desenho a mão livre com aplicação especial do ornato geométrico plano" 
(BARBOSA, 2009, p. 87). Foi a partir desta lei que surgem os exames de admissão para acesso à escola secundária que perduraram até 1971 e, instituíram-se também os exames de admissão para o curso superior, através de provas de vestibular presente até os dias atuais (com menor ênfase), perdendo gradativamente espaço para o ENEM (Exame Nacional do Ensino Médio).

Em 1915, a Reforma Carlos Maximiliano, que vigorou por uma década, manteve a autonomia administrativa das instituições escolares, mas reestabeleceu a responsabilidade do Estado e a ação fiscalizadora do Governo Federal no que tange à formação e fiscalização dos currículos no ensino primário e secundário, avaliando os cursos superiores. A disposição do governo era "moralizar o ensino" (BARBOSA, 2009, p. 91).

Foi nesta reforma que o desenho perdeu seu valor régio, e o professor de desenho passa a ser considerado inferior e desnecessário ao círculo das relações escolares. Segundo a lei: "A nota obtida em exame de desenho visa estimular os estudantes, não influi para a passagem dos alunos para o ano imediato; basta-lhes para a promoção exibir atestado de frequência subscrito pelo professor" (BARBOSA, 2009, p. 92). Assim, pode-se dizer que desde 1915 o ensino da Arte no Brasil começa a apresentar sua decadência, sendo considerado sem importância para ascender aos cursos superiores. Todavia, houve um jogo de interesses para recuperar o status do desenho no âmbito escolar ao aproximá-lo com maior ênfase da geometria desde o ensino primário, visto que para a admissão ginasial, realizava-se uma prova que envolvia conhecimentos geométricos elaborados.

Este movimento de aproximação entre o desenho artístico e a geometria pode ser visto no fragmento que segue, retirado do currículo de Artes Visuais, em pleno ano de 2015, pertencente a uma instituição estadual de ensino, correspondente ao oitavo ano do Ensino Fundamental:

\footnotetext{
a. Traçado e uso das linhas em desenho geométrico;

b. Elementos básicos: pontos, reta e plano;

c. Reta: semirreta, segmentos de reta, posição absoluta, posição relativa, coincidentes, concorrentes, oblíquos, perpendiculares, construção de retas [...] (Instituto Estadual de Ensino, Currículo de Artes Visuais, $8^{\mathrm{a}}$ ano, 2015).
}

Observa-se que há um alargamento gradual dos conceitos que partem do simples ao complexo, o mesmo modelo presente na "Geometria Popular" de Abílio César Pereira Borges, livro reeditado até 1959.

Pode-se dizer que o currículo da Arte no Brasil esteve embalado num movimento de idas e vindas conceituais, cuja ênfase era o desenho livre, desenho geométrico e desenho industrial, deixando poucas brechas para a pintura, escultura e trabalhos manuais múltiplos, 
não há referência à utilização do corpo como instrumento de aprendizagem. A arte estava a serviço de outras disciplinas curriculares, tornando-se subsídio para o desenvolvimento industrial do país.

A Semana de Arte Moderna ocorrida em 1922, influenciada pelo experimentalismo psicológico e os movimentos artísticos: impressionismo, expressionismo, cubismo e neoconcretismo, assume na pessoa de Anita Malfatti e Mário de Andrade uma valorização estética da arte infantil estruturada sobre o método do "deixar fazer", valorizando a expressão espontânea da criança. Há uma valorização do desenho como técnica e a exaltação dos elementos internos expressivos como constituinte da própria forma, mecanismo de expressão e despertar criativo do artista nato (BARBOSA, 2009).

Com o advento do modernismo, defende-se a ideia da arte como instrumento mobilizador da capacidade criadora, ligando imaginação e inteligência. Há influências do pensamento de John Dewey que conduz o ensino desde a observação naturalista até a arte como expressão sensível, introspecção e apreciação dos elementos do desenho. Defende dois processos para o ensino de Artes Visuais: o conhecimento que possibilita articular saberes prévios e novas situações envolvendo pensamento e movimento do corpo e, experiência, compreendida como a mediação entre o sujeito e o conhecimento, sendo uma ação refletida, intencional, planejada que visa perceber os fins para identificar os meios.

A experiência em Dewey é uma totalidade, ao abarcar as individualidades de cada ser que aprende em suas interações culturais, envolvendo saberes, signos, valores e relações sociais, produzindo sentidos. A escola serve para possibilitar uma reconstrução permanente de novas experiências. Uma experiência completa gera um conhecimento, uma consumação impregnada de apreciação e pode culminar num processo de aprendizagem.

Nova ruptura no processo de ensino da Arte no Brasil. Com o Estado Novo há uma interrupção do desenvolvimento da escola nova, da "livre expressão" e retorna o desenho geométrico como conteúdo basilar na escola secundária, valorizando o desenho pedagógico e a cópia de estampas. A partir de 1947 surgem os primeiros ateliês para crianças, orientados por artistas influenciados pelo modernismo e visam liberar a expressão da criança, fomentando o ensino das Artes Visuais em direção ao desenvolvimento da criatividade.

Com a Ditadura Militar em 1964, muitos professores de escolas experimentais foram perseguidos e, aos poucos, a prática de arte nas escolas públicas foi manipulada para trabalhar com desenhos alusivos às comemorações cívicas, religiosas e outras festividades de caráter nacionalista. 
Em 1969 a arte fazia parte dos currículos das escolas particulares seguindo uma linha metodológica de variabilidade técnica, entretanto, eram raras as escolas públicas que desenvolviam um trabalho de arte. Entre 1968 e 1972 as escolas especializadas no ensino de arte, começam a relacionar o desenvolvimento de processos mentais envolvidos na criatividade com a teoria fenomenológica da percepção, bem como o desenvolvimento da capacidade crítica ou da abstração (BARBOSA, 1998).

Em 1971 a Educação Artística torna-se componente curricular obrigatório com a promulgação da lei 5.692/1971 (Lei de Diretrizes e Bases da Educação Nacional), a mesma estabelece a prática da polivalência, ou seja, um mesmo professor deveria possuir conhecimentos de artes visuais, artes cênicas, artes musicais e desenvolver trabalhos voltados a todas estas linguagens artísticas. Para qualificar os docentes, em 1973 foram criados cursos de graduação em Educação Artística e Licenciatura em Artes Plásticas com duração de dois anos, preparando de forma aligeirada professores aptos a ensinar tudo ao mesmo tempo. Ao findar este período, o professor poderia escolher uma habilidade específica (artes plásticas, desenho, artes cênicas, música) e continuar seus estudos, rumo à licenciatura plena (BARBOSA, 1998).

A década de 80 (oitenta) foi turbulenta, com diversos movimentos em prol da escola pública de qualidade, alicerçada numa pedagogia sociopolítica. Na Universidade de São Paulo é criado o primeiro curso de pós-graduação (Mestrado e Doutorado) na linha de pesquisa em Arte/educação sob a orientação de Ana Mae Barbosa, que a partir da década de 90 (noventa) sistematiza a Proposta/Abordagem Triangular para o ensino de Artes Visuais. Pode-se dizer que há uma transição do movimento moderno ao pós-moderno caracterizado pela entrada da imagem, sua decodificação e interpretação na sala de aula, junto à expressividade outrora já conquistada (BARBOSA, 1998).

Richter (2000), em sua tese de doutorado, escreve sobre este campo perigoso que envolve a necessidade de uma ruptura paradigmática entre o ensino de arte moderno focado na forma e processo (reprodução, imitação, cópia do modelo, arte como linguagem), valorizando apenas o ensino da história da arte em detrimento de uma arte contemporânea. Neste enfoque a linguagem artística assume uma nova postura, os elementos aparecem como meios e não como o próprio conteúdo. "A ênfase é dada aos temas, ideias, aspectos sociais, literatura e narrativa. Aspectos como ironia, paródia, metáfora também são levantados" (RICHTER, 2000, p. 36).

Para esta nova arte-educação propõe-se um processo de interpretação da obra de arte, através de seu processo de criação, crítica e compreensão das condições sociais, culturais e 
históricas dos indivíduos que a analisam. Este movimento de análise entre o ensino de arte moderno e pós-moderno ganha ressonância quando se pretende compreender a efervescência das relações atuais, enquanto que o modernismo considera a arte como um fenômeno único descomprometido da experiência estética, o "pós-modernismo vê a arte como uma forma de produção e reprodução cultural, que só pode ser compreendida dentro do contexto e dos interesses das suas culturas de origem e apreciação" (RICHTER, 2000, p. 38).

Enquanto o modernismo trabalha com a gramática visual, a excelência estética e a reprodução de modelos, a arte pós-moderna está aberta às experiências conectadas com a vida, desmanchando as fronteiras entre a arte e o contexto cultural (RICHTER, 2000).

\subsection{Parâmetros Curriculares Nacionais de Artes: os tempos que regem os programas}

Limites, grades, barreiras, cerceamento do conhecimento, regra, norma, lei!? Parâmetros? Metodologias do ensino em artes visuais? Métodos? Arte como linguagem? Arte como comunicação? Professor polivalente: música, teatro, dança, artes plásticas? Arte e ciência? Ciência como racionalidade e arte como sensibilidade, dicotomias? "A arte não representa ou apenas reflete realidade, mas é também realidade percebida, imaginada, idealizada, abstraída" (PCN - BRASIL, 1998, p. 32).

A arte não representa apresenta-se sim como potência de pensamentos. Processos de criação e invenção. Os Parâmetros Curriculares Nacionais (PCNs), do terceiro e quarto ciclo do Ensino Fundamental em Artes Visuais, dissertam sobre os objetivos, metodologias, processo avaliativo, história da arte na educação brasileira e filiam-se as linguagens artísticas.

Demarcam o processo para produção e fruição da arte. Trabalhar arte também é conhecer a obra de arte e o artista, compreendê-la como linguagem e comunicação. O ensino não se restringe à intenção do artista, envolve o campo cultural do artista para entender a sua produção pictórica. É importante aprimorar e desenvolver a percepção para a compreensão estética. A imaginação é um dos subterfúgios que leva à criação. "No caso do conhecimento artístico, o domínio do imaginário é lugar privilegiado de sua atuação: é no terreno das imagens (forma, cor, som, gesto, palavra, movimento) que a arte realiza sua força comunicativa" (BRASIL, 1998, p. 34).

A arte é linguagem e comunicação? Linguagem provém do latim língua, refere-se a um sistema de signos convencionais que tem a intenção de representar a realidade, com fins de possibilitar a comunicação humana, sendo um elemento estruturador das relações entre os 
seres humanos. Comunicação refere-se a uma forma de avisar, informar, notificar, participar de um saber, transmitir, criar correspondências e possibilitar a interação social.

Nos PCNs a arte torna-se conhecimento e a experiência é desmembrada em níveis, não hierárquicos, e pode acontecer independente da ordem, envolvendo processos como fazer, fruir e investigar. O conhecimento é visto como um movimento de aquisição de informações, o fazer artístico resume-se à apropriação poética dos materiais pictóricos, "desenvolvimento de potencialidades: percepção, intuição, reflexão, investigação, sensibilidade, imaginação, curiosidade e flexibilidade" (BRASIL, 1998, p. 37), restringe-se à comunicação e a obra de arte como a produção de signos culturais.

Apesar das limitações deste olhar, os PCNs têm a intenção de tornar vivo o ensino de artes em suas "múltiplas linguagens" (plásticas, teatrais, musicais, dança), contribuindo para a compreensão da $\mathrm{LDBN}^{4} \mathrm{n}^{\circ}$. 9.394/1996, valorizando a formação dos professores, a cultura como subsídio da prática educativa, sendo-a um critério à seleção dos conteúdos: arte como cultura, compreensão das manifestações culturais e artísticas, valorização dos eixos da aprendizagem - fazer, apreciar e contextualizar (BRASIL, 1998).

Para sua elaboração os PCNs partem do ideal de uma escola sócio-interacionistaconstrutivista alicerçada nos estudos de Piaget (epistemologia genética e desenvolvimento sócio-biológico), Vygostsky (escola sócio-histórica e valorização das relações estabelecidas culturalmente) e Ausubel (aprendizagem significativa, compreensão do que se aprende e qual sua importância na vida diária). Na década de 90 (noventa) a ênfase recai sobre a cultura, os métodos e estratégias de aprendizagem, as múltiplas formas de assimilação dos conteúdos, incluindo: "fatos, conceitos, princípios, procedimentos, valores e atitudes" (IAVELBERG, 2003, p. 35).

Os PCNs apresentam, como conteúdos gerais e indispensáveis a todas as linguagens artísticas, a arte como expressão e comunicação, técnicas, procedimentos, elementos básicos de cada linguagem, criação em arte, produtos da arte (bens culturais e bens de consumo), concepção estética e histórica da arte, arte na sociedade (artistas, manifestações, produções, documentações, preservação e espaço artísticos). Pode-se pontuar que há uma mudança de foco que outrora se dedicava apenas ao desenho geométrico e industrial (BRASIL, 1998).

Os currículos passam a priorizar a questão da diversidade nas estratégias individuais que os alunos constroem para aprender e para contemplar conteúdos no âmbito da tipologia de conteúdos, ou seja, saberes de diferentes naturezas são organizados para estruturar as experiências de aprendizagem significativa dos estudantes, e as

\footnotetext{
${ }^{4}$ LDBN - Lei de Diretrizes e Bases da Educação Nacional.
} 
orientações didáticas passam a considerar os métodos de aprendizagem desses saberes pelos estudantes (IAVELBERG, 2003, p. 35).

Ao priorizar a diversidade, valorizam-se as manifestações artístico-sociais e culturais. Trabalha-se com métodos cuja ênfase recai sobre princípios e conceitos, fatos históricos, procedimentos e processos de assimilação conceitual, valores e atitudes.

A cultura passa a demarcar os conteúdos que penetram nos currículos escolares. Há valorização do contexto formativo e aprendente dos estudantes, todavia, esta inserção conceitual mantém-se atrelada a uma ideia que visa o desenvolvimento de valores, normas e atitudes comportamentais, ao incluir conteúdos que tendem a desenvolver o prazer e empenho apreciativo; interesse e respeito por sua produção pictórica e a dos colegas; atitudes de autoconfiança e autocrítica; cooperação, atenção, juízo de valor e respeito; autonomia para a apreciação estética; sensibilidade crítica e reconhecimento dos obstáculos no processo criador (BRASIL, 1998).

Os PCNs de Artes Visuais apresentam verbos imperativos em seus objetivos, que podem ser considerados no processo de elaboração e sistematização curricular em cada instituição escolar, tais como: expressar; representar ideias, emoções e sensações; construir; comunicar-se; interagir com diversos materiais; reconhecer, diferenciar e utilizar técnicas artísticas; desenvolver a autoconfiança; identificar a diversidade dos elementos das linguagens artísticas; apreciar imagens e objetos artísticos; frequentar e utilizar museus, casas de arte, ateliers; compreender, comparar e analisar as multiplicidades artísticas; conhecer e situar profissionais da arte historicamente (BRASIL, 1998).

Interessa ter em mente que o enfoque deste documento é a arte como linguagem, conhecimento e comunicação, "aprendizagem contextualizada, reflexiva e criadora, passou a ser considerada uma das principais metas das novas proposições curriculares" (FERRAZ e FUSARI, 2009, p. 59). Imerso nestas proposições os conteúdos de artes visuais são elaborados com base na produção artístico-visual; no processo de apreciação que ocorre pelo contato sensível; identificação, observação e análise de técnicas; leitura das formas visuais e obras de arte; apreciação por meio da fala, escrita ou registro audiovisual; identificação dos múltiplos sentidos e significados que compõem a imagem visual (BRASIL, 1998).

Além da ênfase na produção, considera-se a valorização cultural e histórica, a partir da observação, investigação, conhecimento, registro, assimilação e reflexão cultural. A pretensão deste documento é instrumentalizar docentes de artes visuais, num processo de reconhecimento valorativo da disciplina de artes em suas múltiplas linguagens, possibilitando a criação de critérios para ensinar, planejar e avaliar. 
Estudar pode ser apaixonante, agradável, instigante e desafiador. Para contribuir com o processo de ensino em artes visuais, os PCNs apresentam-se como balizas que podem ser ultrapassadas, de maneira a problematizar os conceitos artísticos, questionar a arte como linguagem e comunicação, perceber que a experiência não pode ser mensurada e prevista, ela acontece.

Apesar dos PCNs pontuarem a metodologia alicerçada em projetos de ensino, os conteúdos ainda se organizam em "etapas sequenciais", valorizam a exploração de "técnicas" artísticas a partir de uma abordagem didático-pedagógica. Ao transformar a arte em linguagem é possível criar estratégias avaliativas, demarcar os caminhos a percorrer, limitar o processo do aprender.

A incompreensão prática dos PCNs, fizeram emergir no Rio Grande do Sul, nos anos de 2009 a 2012 outra proposta curricular para embasar a prática docente. O referencial curricular "Lições do Rio Grande" aproxima a arte das linguagens, tecnologias e educação física e critica os PCNs por seu caráter ambíguo. Filia-se ao desenvolvimento de competências e habilidades.

Nos anos finais do ensino fundamental é delegado ao ensino de artes duas horas/aula semanais. O ensino de artes visuais está alicerçado na tríade: ler, escrever e resolver problemas. Ler é atribuir sentido à imagem, interpretá-la, decifrá-la, produzir um discurso gráfico, visual e verbal alicerçado em elementos basilares da linguagem visual. Escrever associa-se ao ato de criar, elaborar uma poética visual própria ao representar vivências pessoais ou grupais, criação de portfólios, textos e pesquisas sobre a história da arte. Resolver problemas inclui solucionar os desafios de produção apresentados pelo professor, na necessidade de contextualizar a proposta de trabalho com os recursos disponíveis e pensar artisticamente (RIO GRANDE DO SUL, 2009).

Para tornar possível o desenvolvimento da leitura, escrita e resolução de problemas, o referencial curricular sistematiza a aprendizagem de artes visuais em temas estruturantes, como apresentado na imagem abaixo: 


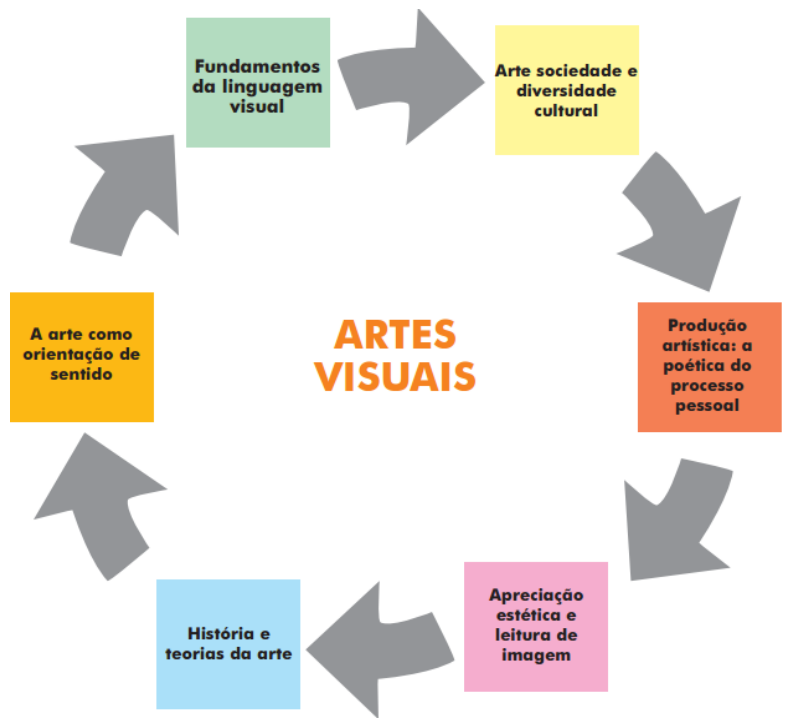

Figura 1: Sistematização curricular do ensino de Artes Visuais RIO GRANDE DO SUL - Lições do Rio Grande (2009, p. 56).

Este intrincado esquema de temas estruturantes não destoa dos PCNs, apresenta outra roupagem ao pontuar de forma específica o que e como se deve desenvolver cada conteúdo nas aulas de artes visuais.

A diversidade cultural envolve reconhecer o patrimônio cultural do entorno escolar, os espaços de legitimação da arte como museus, ateliers, bienais e curadorias; o processo de produção artística pessoal torna possível que o estudante experimente materiais tradicionais e inovadores (não tradicionalmente reconhecidos no universo da arte); a apreciação e a leitura da imagem instiga compreender técnicas, movimentos artísticos e contextos de produção; a história da arte surge como meio de pontuar as transformações artísticas e seu movimento reivindicatório; e, por fim, a arte como produção de significado e não sensação, alicerçada na ótica de intertextualidade ao relacionar arte e vida cotidiana, envolto pela problemática da vida contemporânea (RIO GRANDE DO SUL, 2009).

Este referencial enfatiza a análise e interpretação crítica das artes através da produção, apreciação e contextualização, demarcadores já presentes nos PCNs. Propõe como estratégia para a ação, projetos de trabalho e estudos, sugere que estes se desenvolvam por meio de "temas de estudo", suscitados em debates, análises e ações cooperativas entre estudantes e professores. Os conteúdos de artes visuais são os consagrados pela história curricular brasileira (desenho geométrico, linguagem artística, livre expressão, apropriação de técnicas, conhecimento da história da arte, releitura de imagens, dentre outros) e a demanda proveniente do interesse dos estudantes.

\subsection{Base Nacional Comum Curricular: onde chegamos?}


A nova configuração curricular brasileira que, em tese, ignora as peculiaridades regionais e propõe uma BNCC - Base Nacional Comum Curricular, estrategicamente consolidada por blocos temáticos amplos, dispersos e indefinidos na área das Ciências Humanas, apresenta um rol de objetivos genéricos seguido de uma lista de habilidades.

Ao focar o ensino em habilidade e competências está assumindo um papel científico, objetivo e sistemático, contrariando as dimensões que descreve como estimuladoras da ação artística, este processo minimiza a possibilidade de criação docente, se este não estiver apto a compreender as $n$ possibilidades de cada objetivo e os vislumbrar equivocadamente como conteúdos.

A BNCC, aprovada no final do ano de 2017 possui dois anos para sua inserção e adequação escolar, em especial, na elaboração dos planos de ensino. Este cenário é comum nas escolas públicas que vivem à mercê da legislação e as mudanças curriculares que ocorrem de forma contínua; movimento que impossibilita o desenvolvimento de um trabalho coerente e sequencial de forma a perceber se há, ou não, efeitos benéficos desta transformação na estrutura educacional.

A educação pode ser o encontro de singularidades, de coletividades, que valorizam a potência de pensar e agir, da alteridade (colocar-se no lugar do outro e tentar perceber o seu ponto de vista). Importa notar que a consolidação curricular forma corpos, formata pensamentos, constitui profissionais, desestabiliza singularidades e reafirmam modelos positivistas, autômatos, técnicos e instrumentais no espaço educacional. Afirmações clichês de uma percepção docente engajada com o aprender, mas nebulosa quando não há uma percepção do currículo e da formação inicial como meio, processo, vida e pulsão.

Nem tudo o que está descrito na BNCC precisa ser desconsiderado por seu viés produtivista, interessa destacar as dimensões que propõe, as quais se forem desenvolvidas de uma forma corporalmente engajada e promotora de sensações torna-se potente ao âmbito escolar: criação, crítica, estesia, expressão, fruição e reflexão. Não existe uma linearidade nestas ações, mas um desenvolvimento dinâmico que pode auxiliar a existência de uma experiência no espaço escolar.

Cada uma das dimensões propostas envolve saberes diferenciado, o ato de criar não pode ser resumido ao processo de releitura de imagens, imitação, repetição de um modelo, envolve um método amplo de gestar uma ideia para transformá-la em materialidade. Deleuze e Guattari (2010) destacam que ter uma ideia é criar, envolve preparação, um complexo de sensações ao dispor-se à vivência, não pode ser resumido em um sistema de automatização da 
proposta de recriar o criado, reviver o vivido, sem gerar pensamentos. Imerso nesta conjuntura, cabe questionar: como criar em arte ao se viver um espaço escolar com tempos reduzidos e normas sistematizadas?

A primeira dimensão da $\mathrm{BNCC}$ já se mostra problemática, em seguida propõe a ação crítica, o que instiga o estudante a questionar, ler a imagem de forma sociocultural, envolverse num processo de percepção e existência estética. Por outro lado à lei propõe a descrição das impressões, o estabelecimento de relações por meio de estudo e pesquisa da obra e visa à existência de um pensamento propositivo. Como propor sem a existência de um embasamento teórico? A obra de arte vale por si mesma, é um ser em si - destaca Deleuze e Guattari (2010), por que torná-la linguagem? Sensações fazem parte da arte que é composta por perceptos e afectos, um conjunto de percepções e sensações que se tornam independente do artista, independente da crítica vazia, mas dependente do espectador que participa da obra (DELEUZE, GUATTARI, 2010).

A estesia é apresentada como outra dimensão e um avanço qualitativo em relação às leis curriculares precedentes, talvez a mais impactante e dinâmica de todas, pois em um mundo formado pela indiferença, individualidade, solidão e anestesia, colocar o corpo em funcionamento e provocar um saber vibrátil é fascinante. O corpo mostra-se como protagonista da experiência, provoca-se a existência do "eu corpo", corrompe-se a dicotomia cartesiana entre corpo e alma, intelecto e carnalidade. A estesia é a vivência completa do ser.

"A estesia é como uma poética da dimensão sensível do corpo que suscita em absoluta singularidade uma experiência sensível com objetos, lugares, condições de existência, seres, comportamentos, ideias, pensamentos, conceitos" (PICOSQUE, MARTINS, p. 35, 2012). Para tornar-se viável a presente dimensão será preciso aprimorar os saberes docentes, tornando-os conhecedores de seu corpo, eis um desafio para o desenvolvimento desta ótica curricular.

Todavia na esteira do pensamento destaca a expressão que pode ser um complemento do ato de criação, ou uma forma reducionista de ver as artes como linguagem. A base curricular destaca o expressar como uma forma de manifestar a subjetividade através da linguagem artística, usurpando o processo de criação que ocorre envolto por um agir estésico. Se a expressão é apenas a criação/reprodução material da arte, não se mostra necessário o processo de apreensão contextual e vivência artística.

A fruição é vista em uma ótica reducionista de prazer ou dispor-se a conhecer a cultura e as múltiplas artes. Finaliza as dimensões com o termo reflexão, o ato de olhar a si mesmo e 
verificar o que aprendeu através da análise, um sistema de fragmentação em partes do todo complexo ou a interpretação que, geralmente, configura uma opinião.

No verbo da lei, pode-se verificar o perfil disperso e ao mesmo tempo reducionista do currículo, ao se distender as possibilidades de aprendizagem retoma-se o foco histórico dos currículos de artes visuais que reduz a arte a comunicação:

\begin{abstract}
As Artes Visuais são os processos e produtos artísticos e culturais, nos diversos tempos históricos e contextos sociais, que têm a expressão visual como elemento de comunicação. Essas manifestações resultam, de explorações plurais e transformações de materiais, de recursos tecnológicos e de apropriações da cultura cotidiana. (BNCC, p. 192, 2017).
\end{abstract}

Importa lembrar que o conhecimento científico possibilita ao sujeito uma inserção política em seu meio sociocultural, provocando um sistema de participação e compreensão cidadã, restringir os conceitos a serem debatidos e apreendidos no âmbito educacional é usurpar o direito ao conhecimento, não como moeda de troca, mas como uma possibilidade de organização da luta social e política à medida que se percebe o saber científico como provisório, cultural e histórico. Reduzir as artes visuais à comunicação é um empecilho ao contexto educacional e um regresso ao desenvolvimento que as artes galgaram nos anos de 1980.

\title{
3. Considerações Finais
}

Será que há possibilidades de aprender artes visuais, com o currículo escolar que a escola apresenta? É possível viver experiências, no processo de aprendizagem em artes visuais, alicerçado no currículo dogmático que defende o ensino do desenho geométrico, dos ângulos, da perspectiva cônica e linear, do reconhecimento dos sólidos geométricos e sua planificação?

Ou melhor, pensar o momento atual no qual os conteúdos escolares estão alicerçados na BNCC, o que gera infindáveis dúvidas. Será mais uma forma de minimizar a potência do aprender? Uma estratégia de desvalorizar o processo investigativo e formativo? Ou pode tornar-se um instrumento que impulsiona o ato criador a romper com o modelo proposto levando a instigar, desafiar e usufruir do conhecimento como veículo para transformar o âmbito social?

O Brasil vivenciou um patchwork de normativas e leis curriculares, de forma a tangenciar um ensino que pudesse servir para algo, colocando a arte no plano da funcionalidade. Vale destacar que está enormidade de mudanças curriculares foram compreendidas de forma parcial e provisória por muitos educadores, ação que acarretou a 
promulgação da BNCC (documento que estava sendo gestado desde a década de 80 ), todavia ele absorve e destaca um perfil restrito e difuso para o ensino de artes e suas linguagens.

Com a Ditadura Militar e a promulgação da Lei 5.692/1971 o ensino de artes passou a compor o currículo, o ensino era voltado à técnica e ao processo de profissionalização, sendo obrigatório aos discentes. Neste período a Sociologia e a Filosofia haviam sido removidas do currículo e a Arte assumiu o desafio de provocar a ação crítica e o pensamento. O ensino era formado por listas de conteúdos a serem ministradas, impedindo qualquer possibilidade de autonomia docente, fazendo desaparecer a intenção de provocar o senso crítico.

Das Belas Artes as Artes Visuais, passando pela Educação Artística e a Artes Plásticas, destaca-se que o ensino de artes percorreu caminhos tortuosos, desde o desenho geométrico, a cópia de fichas de desenhos, até o laissez-faire (deixar fazer). A busca pela valorização e reconhecimento das artes envolveu romper com a lógica do "dom inato", com a consideração da arte como uma atividade de lazer, momento de descanso, ocupação sexista, entre outras formulações pejorativas.

A formação do docente ocorria de forma aligeirada, evidenciando uma despreocupação com o ensino e o valor das artes, neste contexto a história da arte, apreciação, fruição, viver experiências e experimentar a estesia não estavam presentes, nem estava em questionamento promover o pensamento do alunado e sua ação crítico-social.

Vale destacar que o lugar hierárquico da disciplina de Artes ainda se mantém aquém em relação às disciplinas de linguística, Matemática e Ciências. Na rede pública de ensino visualiza-se um contínuo processo de desvalorização da imagem, do som, do movimento, da percepção estética como fontes de conhecimento educacional e pessoal. O desenvolvimento das Artes mantém-se por solavancos e imposições legais, ação que dificulta o processo de aprimoramento e desenvolvimento de um saber estético, por outro lado, vale lembrar que o ensino de Artes ocorre imerso em lutas políticas, negociações, disputa por espaços, sentidos, tempos, valores o que garantiu algumas conquistas vivenciadas pelos arte-educadores.

Pode-se dizer que a BNCC é mais uma estratégia governamental para tolher e limitar o processo de criação de um ensino embasado na ação crítica, processo criador e habilidade comunicativa através da produção de sentidos. Neste contexto a interferência do poder privado nas relações governamentais e formulações curriculares pode vir a suplantar o caminho trilhado e as conquistas dos arte-educadores, tornando a lei apenas uma forma de mascarar os ditames e imposições de um sistema governamental retrógrado.

A ideia de uma base nacional comum curricular não contempla a diversidade e inibe a compreensão cultural de cada região, o processo de valorização das diferenças, bem como não 
irá solucionar os problemas educacionais brasileiros. A lei restringe as conquistas presente nos Parâmetros Curriculares Nacionais e torna o ensino de artes um rol de ações sistemáticas a serem reproduzidas.

Num momento de suspensão do pensamento podem-se destacar os dilemas que a BNCC coloca ao ensino brasileiro, surge com a intenção interessante de horizontalizar o ensino nas escolas do Brasil, mas, a relação entre escola pública e escola privada continuará a ser um abismo com níveis discrepantes de qualidade, sabe-se que a escola privada investe em qualidade, pois assim recebe investimentos do poder público. De forma análoga as classes sociais mais abastadas continuarão a ter acesso aos saberes de forma privilegia, sem precisar se submeter a uma base curricular dispersa e contraditória. Os suposto conteúdos horizontalizados são selecionados de qual maneira? A partir de quais princípios teóricos, curriculares, sociais, políticos e econômicos? Ensinar artes requer espaço, materiais plástico, conhecimentos teóricos, para este desenvolvimento os docentes conseguirão espaço nas escolas? Ou serão mantidos à margem da produção do conhecimento? Sem querer concluir ou responder os presentes questionamentos, deixa-se em aberto a escrita para provocar novos questionamentos acerca da história do currículo de Artes no Brasil e articular ações que desembocaram na atual problemática da $\mathrm{BNCC}$, visto que até o momento não se conseguiu resolver os problemas educacionais das escolas brasileiras.

\section{Referências}

BARBOSA, Ana Mae. Tópicos Utópicos. Belo Horizonte: C/Arte, 1998. 200 p.

BARBOSA, Ana Mae. Arte-educação no Brasil. $6^{\mathrm{a}}$ ed. São Paulo: Perspectiva, 2009.

BRASIL. PCN de Arte para as séries finais do ensino fundamental - $5^{a}$ a $8^{a}$ séries. Disponível em: http://portal.mec.gov.br/seb/arquivos/pdf/arte.pdf. Capturado em: 21. abril.2011.

BRASIL. BNCC - Base Nacional Comum Curricular. Ensino Fundamental. Disponível em: http://basenacionalcomum.mec.gov.br/download-da-bncc. Capturado em: dezembro, 2017.

BERTICELLI, Ireno Antonio. Currículo: Tendência e Filosofia. In: COSTA, Marisa Vorraber (org.). O Currículo: nos limiares do contemporâneo. Rio de Janeiro: DP\&A, 1998. p. 159176.

AMORIM, Antonio Carlos (org.). Teóricos e o Campo do Currículo. Campinas, SP: FE/UNICAMP, 2012, p. 120-140 (e-book GT Currículo).

CORAZZA, Sandra Mara; SILVA, Tomaz Tadeu. Composições. Belo Horizonte: Autêntica, 2003. 
CORAZZA, Sandra Mara. Artistagens: Filosofia da diferença e educação. Belo Horizonte: Autêntica, 2006.

DELEUZE, Gilles. Diferença e Repetição. São Paulo: Graal. 1998.

Zahar, 2007.

Lógica da Sensação. Equipe de Trad. Roberto Machado (coord.). Rio de Janeiro:

DELEUZE, Gilles; GUATTARI, Félix. O que é a Filosofia? 3 ed. São Paulo: Editora 34, 2010 .

DELEUZE, Gilles; GUATTARI, Félix. Mil Platôs: capitalismo e esquizofrenia. Vol. 1. Tradução de Aurélio Guerra Neto e Célia Pinto Costa. Rio de Janeiro: Ed. 34, 1995.

FERRAZ, Maria Heloísa C. de T.; FUSARI, Maria F. de Rezende e. Metodologia do Ensino de Arte: fundamentos e proposições. $2^{\circ}$ ed. rev. e ampl. São Paulo: Cortez, 2009.

FOUCAULT, Michel. As Palavras e as Coisas. 9. ed. São Paulo: Martins Fontes, 2007.

GREINER, Christine. O corpo. Pistas para Estudos Indisciplinares. São Paulo: Annablume, 2005.

GALLO, Sílvio. Currículo (entre) imagens $e$ saberes. Disponível in: http://unicamp.academia.edu/SilvioGallo/Papers. Acesso: março.2015.

IAVELBERG, Rosa. Para Gostar de Aprender Arte: sala de aula e formação de professores. Porto Alegre: Artmed, 2003.

PASSOS, Eduardo; KASTRUP, Virgínia; ESCÓSSIA, Liliana da (orgs.). Pistas do Método da Cartografia: pesquisa-intervenção e produção de subjetividades. Porto Alegre: Suiina, 2009.

PICOSQUE, Gisa; MARTINS, Mirian Celeste. Revelações do Corpo: estesia. conhecimento. In: . Mediação Cultural para Professores Andarilhos da Cultura. $2^{\mathrm{a}}$ ed. São Paulo: Intermeios, 2012. pp.33-39.

RICHTER, Ivone Mendes. Interculturalidade e Estética do Cotidiano no Ensino das Artes Visuais. Campinas: SP, 2000 (tese de doutorado).

RIO GRANDE DO SUL. Referenciais Curriculares do Estado do Rio Grande do Sul: Linguagens, Códigos e suas Tecnologias. Secretaria do Estado da Educação. Porto Alegre: SEDP, 2009.

ROLNIK, Suely. Cartografia Sentimental, transformações contemporâneas do desejo. Editora Estação Liberdade, São Paulo, 1989.

ROY, Kaustuv. Gradientes de Intensidade: o espaço háptico deleuziano e os três "erres" do currículo. In: Educação e Realidade. jul/dez, 2002, nº 27: 89-109. 
SACRISTÁN, Gimeno J. Poderes Instáveis em Educação. Educação Teoria e Prática. Porto Alegre: Artmed Editora, 1999.

SACRISTAN, J. Gimeno. O Currículo, uma reflexão sobre a prática. Porto Alegre: Editora Artmed, 2000.

SILVA, Tomaz Tadeu da. O Currículo como Fetiche: a poética e a política do texto curricular. $1^{\mathrm{a}}$ ed. $4^{\mathrm{a}}$ reimp. Belo Horizonte: Autêntica, 2010. 